\title{
ÁREAS VERDES URBANAS: UM ESTUDO DE REVISÃO E PROPOSTA CONCEITUAL
}

\author{
Danúbia Caporusso Bargos ${ }^{1}$, Lindon Fonseca Matias ${ }^{2}$ \\ (recebido em 18.11.2010 e aceito para publicação em 15.09.2011)
}

\section{RESUMO}

A busca pelo desenvolvimento de novas práticas e reflexões relacionadas ao planejamento urbano tem sido evidenciada no Brasil e no mundo pelo elevado número de pesquisas e estudos técnicos e científicos realizados nos últimos anos. Muitos desses estudos apontam a vegetação intraurbana como importante indicador da qualidade ambiental nas cidades devido às funções ecológicas, estéticas e de lazer que ela pode exercer. Neste contexto, a vegetação urbana recebe diferentes nomenclaturas que são utilizadas indistintamente como sinônimos do termo áreas verdes, quando na realidade, em muitos casos, não o são. O presente artigo busca contribuir para o debate teórico e conceitual relacionado ao tema áreas verdes urbanas por meio da realização de uma revisão e proposição para adequação do termo em questão.

Palavras-chave: Áreas verdes; Espaço urbano; Conceito; Qualidade ambiental.

\footnotetext{
${ }^{1}$ Mestre em Geografia pelo DGEO/UNICAMP. Doutoranda em Geografia no Departamento de Geografia do Instituto de Geociências da Universidade Estadual de Campinas - UNICAMP. danubia@ige.unicamp.br.

${ }^{2}$ Doutor em Geografia pela FFLCH/USP. Professor do Departamento de Geografia do Instituto de Geociências da Universidade Estadual de Campinas - UNICAMP. lindon@ige.unicamp.br.

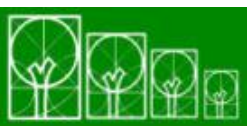

$\mathbf{S} \cdot \mathbf{B} \cdot \mathbf{A} \cdot \mathbf{U}$ Soc. Bras. de Arborização Urbana

REVSBAU, Piracicaba - SP, v.6, n.3, p.172-188, 2011
} 


\section{URBAN GREEN AREAS: A REVIEW AND CONCEPTUAL PROPOSAL}

\section{ABSTRACT}

The development of new practices and reflections related to urban planning in Brazil and in the world, has been made evident by the large amount of researches, technical and scientific studies carried out in the recent years. Several of those studies indicate the intra-urban vegetation as an important indicator of the environmental quality in cities due to its ecological, aesthetic and recreational functions that it can exert. In this context, urban vegetation has different classifications used indistinctly as synonyms of the term green areas, when in reality they are not. This paper aims to contribute to the theoretical and conceptual debate related to the theme urban green areas by a review and propositions for the adjustment of the term.

Keywords: Green areas; Urban space; Concept; Environmental quality.

\section{INTRODUÇÃO}

Desde a década de 1970 as cidades brasileiras têm sofrido as mais intensas transformações. A busca pela compreensão da diversidade dos aspectos do espaço urbano, relacionados às suas dimensões socioambientais, tornou-se uma preocupação cada vez mais presente para o planejamento e a gestão urbana. Os temas relacionados à qualidade ambiental das áreas urbanas vêm sendo debatidos por diversos pesquisadores nos níveis técnicos e científicos. Dentre os temas de relevância, a vegetação intraurbana ganhou destaque nos últimos anos devido às funções que esta pode exercer na melhoria das condições do ambiente urbano.

Embora a vegetação seja considerada por diversos pesquisadores como um importante indicador de qualidade ambiental urbana é possível notar divergências conceituais entre aqueles que estudam o tema, pois termos como áreas verdes, espaços livres, áreas de lazer, por exemplo, são utilizados indistintamente como (4) (P)

$\mathbf{S} \cdot \mathbf{B} \cdot \mathbf{A} \cdot \mathbf{U}$ Soc. Bras. de Arborização Urbana

REVSBAU, Piracicaba - SP, v.6, n.3, p.172-188, 2011 
sinônimos para referência à presença de áreas verdes, quando na realidade não o são necessariamente.

Mesmo com a ausência de uma definição consensual, o termo mais utilizado para designar a vegetação urbana é "áreas verdes". O problema da falta do consenso sobre esta terminologia se reflete, entre outras coisas, nas tentativas de comparações entre os variados índices de áreas verdes (IAV), obtidos por meio do emprego de diversas metodologias para diferentes cidades.

No intuito de contribuir para o debate das reflexões teóricas e metodológicas relacionadas ao assunto este artigo apresenta uma revisão conceitual e uma proposta de adequação para o termo áreas verdes urbanas.

\section{Áreas Verdes Urbanas: Revisão Conceitual}

Conforme Nucci (2001), um atributo muito importante, porém negligenciado no desenvolvimento das cidades, é o da cobertura vegetal, pois além de todas as necessidades que o ser humano tem em relação à vegetação é importante lembrar que as cidades estão cada vez mais poluídas, e esta poluição, principalmente no ar e nos rios, pode ser reduzida substancialmente preservando-se a vegetação local.

Os termos áreas verdes, espaços/áreas livres, arborização urbana, verde urbano, têm sido frequentemente utilizados no meio científico com o mesmo significado para designar a vegetação intraurbana. No entanto, pode-se considerar que a maioria deles não são sinônimos, e tampouco se referem aos mesmos elementos.

A falta de consenso em relação ao termo áreas verdes se evidencia, entre outras coisas, na dificuldade para o mapeamento e classificação/categorização dessas áreas, além das tentativas de comparações entre os diferentes índices de áreas verdes (IAV) obtidos segundo o emprego de diferentes metodologias retratando localidades diversas. A necessidade do conhecimento dessas áreas no ambiente urbano destaca-se devido às funções que elas desempenham na melhoria das 
condições ambientais e de vida da população ${ }^{3}$, à diversificação da paisagem construída, dentre outras ${ }^{4}$.

Cavalheiro e Del Picchia (1992) consideram que, do ponto de vista conceitual, uma área verde é sempre um espaço livre e que o termo espaço livre deveria ser preferido ao invés de áreas verdes, pois segundo os autores é um termo mais abrangente que inclui ainda as águas superficiais. Para eles,

Os espaços livres desempenham basicamente papel ecológico, no amplo sentido, de integrador de espaços diferentes, baseando-se, tanto no enfoque estético, como ecológico e de oferta de áreas para 0 desempenho de lazer ao ar livre. (CAVALHEIRO; DEL PICCHIA, 1992, p. 31).

Para Geiser et al. (1975, p. 30) (apud CAVALHEIRO; DEL PICCHIA, 1992), as áreas verdes são "[...] áreas com vegetação fazendo parte dos equipamentos urbanos, parques, jardins, cemitérios existentes, áreas de 'pequenos jardins', alamedas, bosques, praças de esportes, 'playgrounds', 'play-lots', balneários, 'camping' e margens de rios e lagos".

Estas duas definições já seriam necessárias para explicitar a complexidade da temática. Os primeiros autores não deixam claro se as áreas verdes devem ou não ser constituídas por vegetação, enquanto os últimos não mencionam o porte de vegetação que deveria ser predominante nestas áreas (arbórea, arbustiva, herbácea).

Questionamentos parecidos podem ser levantados para Toledo e Santos (2008), que consideram que as áreas verdes têm papel fundamental na qualidade de vida da população e são espaços destinados à preservação ou implantação de vegetação ou ao lazer público; e também para Hardt (1994) (apud HULSMEYER; SOUZA, 2007), que considera que as áreas verdes devem ser áreas livres na cidade e que apresentam características predominantemente naturais, independentemente do porte da vegetação. Neste caso, os primeiros autores não esclarecem se as áreas

\footnotetext{
3 Jesus e Braga (2005) ressaltam que a vegetação, enquanto um indicador de qualidade ambiental, atua associada a outros indicadores (qualidade do ar, água, solos, fauna e clima) como elemento indispensável ao equilíbrio, seja na manutenção de algumas condições vigentes desejáveis, seja nas ações que visem a melhoria da qualidade de vida em áreas comprometidas.

${ }^{4}$ Segundo Loboda e De Angelis (2005) a qualidade de vida urbana está diretamente atrelada a vários fatores que estão reunidos na infraestrutura, no desenvolvimento econômico-social e àqueles ligados à questão ambiental. "No caso do ambiente as áreas verdes públicas constituem-se elementos imprescindíveis para o bem estar da população, pois influencia diretamente a sua saúde física e mental". (LOBODA e DE ANGELIS, 2005, p.131)
} 
verdes, quando destinadas ao lazer público, devem ser constituídas predominantemente por vegetação. Já os segundos consideram como tal quaisquer áreas que apresentem vegetação, sendo independente do porte.

Contrários a esta idéia, Moreiro et al. (2007, p. 20) entendem que:

[...] as áreas verdes englobam locais onde predominam a vegetação arbórea, praças, jardins e parques, e sua distribuição deve servir a toda população, sem privilegiar qualquer classe social e atingir as necessidades reais e os anseios para o lazer, devendo ainda estar de acordo com sua estrutura e formação (como idade, educação, nível sócio-econômico). [sem itálico no original]

Outra questão relacionada às concepções anteriores é quanto à propriedade dessas áreas. Elas devem ser de propriedade pública ou privada? Demattê (1997) (apud TOLEDO; SANTOS, 2008) emprega a expressão áreas verdes a diversos tipos de espaços urbanos que podem ser públicos ou particulares e são abertos, acessíveis e relacionados com saúde e recreação.

Lima et al. (1994) consideram que é necessário um esforço para que os termos utilizados para classificação da vegetação urbana sejam discutidos de forma convergente. Para eles, espaço livre é um termo mais abrangente que áreas verdes, e admitem que entre os espaços livres tem-se:

$\checkmark$ Área verde: onde há o predomínio de vegetação arbórea. Devem ser consideradas as praças, os jardins públicos e os parques urbanos, além dos canteiros centrais e trevos de vias públicas, que tem apenas funções estéticas e ecológicas. Porém, as árvores que acompanham o leito das vias públicas não se incluem nesta categoria. Os autores apontam que as áreas verdes, assim como todo espaço livre, devem também ser hierarquizadas, segundo sua tipologia (privadas, potencialmente coletivas ou públicas) e categorias.

- Parque Urbano: são áreas verdes, maiores que as praças e jardins, com função ecológica, estética e de lazer.

- Praça: pode não ser considerada uma área verde caso não tenha vegetação e seja impermeabilizada. Quando apresenta vegetação é considerada jardim, e como área verde sua função principal é de lazer. 
$\checkmark$ Arborização Urbana: são os elementos vegetais de porte arbóreo tais como árvores no ambiente urbano. As árvores plantadas em calçadas fazem parte da Arborização Urbana, no entanto, não integram o Sistema de Áreas Verdes.

O sistema de áreas verdes é entendido como integrante do sistema de espaços livres. Esta ideia é sustentada também por Nucci (2001) que denomina estas áreas como um subsistema do sistema de espaços livres e que devem fornecer possibilidade de lazer à população.

De acordo com este entendimento e considerando as áreas verdes como uma categoria dos espaços livres de construção, Mazzei et al. (2007, p. 35) ressaltam que estes termos não são sinônimos e que o planejamento das áreas verdes visa "[...] atender à demanda da comunidade urbana por espaços abertos que possibilitem a recreação, o lazer e a conservação da natureza". Em suas concepções,

[...] as áreas verdes não são necessariamente voltadas para a recreação e o lazer, objetivos básicos dos espaços livres, porém devem ser dotadas de infraestrutura e equipamentos para oferecer opções de lazer e recreação às diferentes faixas etárias, a pequenas distâncias da moradia (que possam ser percorridas a pé) (MAZZEI et al.., 2007, p. 39).

Um aspecto importante, porém negligenciado nas definições expostas anteriormente, está relacionado à permeabilidade ${ }^{5}$ das áreas verdes. Hardt (1994), citado por Huksmeyer e Souza (2007), considera que a permeabilidade do solo em áreas urbanas está normalmente relacionada aos espaços naturais, demonstrando, na maioria das vezes, melhoria na qualidade ambiental. Muitas das áreas permeáveis também são espaços livres públicos.

Cavalheiro et al. (1999, p. 7) recomendaram em um Boletim Informativo da Sociedade Brasileira de Arborização Urbana (SBAU) que a "[...] vegetação e solo permeável (sem laje) devem ocupar, pelo menos, 70\% da área total de uma área verde". Guzzo (2006, p. 21) ressaltou que as áreas verdes são "[...] um tipo especial de espaço livre urbano onde os elementos fundamentais de composição são a vegetação e o solo livre de impermeabilização" e que essas áreas devem ser

${ }^{5}$ O termo permeabilidade está sendo utilizado de forma simples para designar espaços livres de
construção, sem considerar as características do tipo de solo encontrado nessas áreas. 
constituídas por "[...] pelo menos $70 \%$ do seu espaço por áreas vegetadas com solo permeável".

Um fator importante a ser considerado nas afirmações tanto de Cavalheiro et al. (1999) como de Guzzo (2006) está relacionado ao valor (70\%) estabelecido para a área com vegetação e solo livre de impermeabilização das áreas verdes. Trata-se de vegetação "e" solo permeável (sem laje) ocupando $70 \%$ da área total, ou vegetação "com" solo permeável totalizando $70 \%$ da área total? Embora os autores não justifiquem qual a metodologia e quais os parâmetros utilizados para o estabelecimento do valor mencionado, é notória a reprodução desta recomendação. Seria importante ao se adotar este tipo de recomendação o detalhamento do tipo de solo e de vegetação considerados, pois se sabe que os diferentes tipos de solo e de vegetação apresentam características variadas o que faz com que estes apresentem propriedades também diversas quanto ao caráter de permeabilidade. É importante ressaltar que, embora simplificada, a recomendação feita pelos autores trouxe contribuição para os estudos relacionados à temática e que, passados mais de dez anos de sua publicação, deve ser aprimorada a partir de estudos e pesquisas que busquem justificar os valores recomendados.

Anteriormente, Oliveira (1996) já havia considerado a questão da permeabilidade do solo nas áreas verdes. Para ele o conceito de áreas verdes, para ser completo, necessita descrever suas estruturas e enfatizar, sobretudo, a importância que elas têm em termos de suas funções (ecológicas, estéticas, econômicas e sociais). Em seu trabalho o autor definiu essas áreas como:

[...] áreas permeáveis (sinônimos de áreas livres [de construção]), públicas ou não, com cobertura vegetal predominantemente arbórea ou arbustiva (excluindo-se as árvores no leito das vias públicas) que apresentem funções potenciais capazes de proporcionar um microclima distinto no meio urbano em relação à luminosidade, temperatura e outros parâmetros associados ao bem-estar humano (funções de lazer); com significado ecológico em termos de estabilidade geomorfológica e amenização da poluição e que suporte uma fauna urbana, principalmente aves, e fauna do solo (funções ecológicas); representando também elementos esteticamente marcantes na paisagem (função estética), independentemente da acessibilidade a grupos humanos ou da existência de estruturas culturais como edificações, trilhas, iluminação elétrica, arruamento ou equipamentos afins; as funções ecológicas, sociais e estéticas poderão redundar entre si ou em benefícios financeiros (OLIVEIRA, 1996, p. 17). (grifo dos autores). 
Considerando a diversidade de conceitos atribuídos ao termo áreas verdes pode-se dizer que, neste aspecto, torna-se cada vez mais difícil elaborar um planejamento urbano que atenda às necessidades da sociedade, que vive em ambientes cada vez mais artificiais, e evitar o declínio da qualidade de vida nas cidades. A necessidade de uma padronização e adequação mínima do conceito de áreas verdes urbanas, ainda que sem conhecer as especificidades de cada local, fazse latente nos dias atuais visando garantir uma compreensão adequada sobre os problemas a serem enfrentados e também para permitir uma correta intervenção nos espaços urbanos com vistas à manutenção e preservação dessas áreas.

\section{Funções das áreas verdes}

A manutenção das áreas verdes urbanas sempre foi justificada pelo seu potencial em propiciar qualidade ambiental à população. Ela interfere diretamente na qualidade de vida dos seres por meio das funções sociais, ecológicas, estéticas e educativas, que elas exercem para amenização das consequências negativas da urbanização.

Diversos autores, dentre eles Cavalheiro e Del Picchia (1992), Lima et al. (1994), Oliveira (1996), Nucci (2001), Vieira (2004), Toledo e Santos (2008), citam vários benefícios que as áreas verdes podem trazer ao convívio nas cidades, como: controle da poluição do ar e acústica, aumento do conforto ambiental, estabilização de superfícies por meio da fixação do solo pelas raízes das plantas, interceptação das águas da chuva no subsolo reduzindo o escoamento superficial, abrigo à fauna, equilíbrio do índice de umidade no ar, proteção das nascentes e dos mananciais, organização e composição de espaços no desenvolvimento das atividades humanas, valorização visual e ornamental do ambiente, recreação, diversificação da paisagem construída. A vegetação tem efeitos diretos sobre a saúde mental e física da população. Oliveira (1996) salienta ainda que estes efeitos contribuem para a valorização de áreas para convívio social, valorização econômica das propriedades e para a formação de uma memória e do patrimônio cultural.

Para Milano (1990, apud VIEIRA, 2004) a principal função do sistema de áreas verdes urbanas não deve ser apenas a criação de refúgios para que as pessoas possam "escapar" da cidade. Além disso, essas áreas devem possibilitar à população 
momentos de lazer e recreação em convívio com a natureza, respeitando sua vivência urbana e contato com outras pessoas. Oliveira (1996, p. 11) argumenta que o "[...] estilo de vida urbano e a estrutura cultural das cidades são elementos associados à tendência ao sedentarismo, aumentando a demanda por áreas verdes e espaços para recreação".

Vieira (2004) admite que as áreas verdes tendem a assumir diferentes papéis na sociedade e suas funções devem estar interrelacionadas no ambiente urbano, de acordo com o tipo de uso a que se destinam (Figura 1).

Figura 1. Funções das Áreas Verdes Urbanas.

Figure 1. Functions of Urban Green Areas.

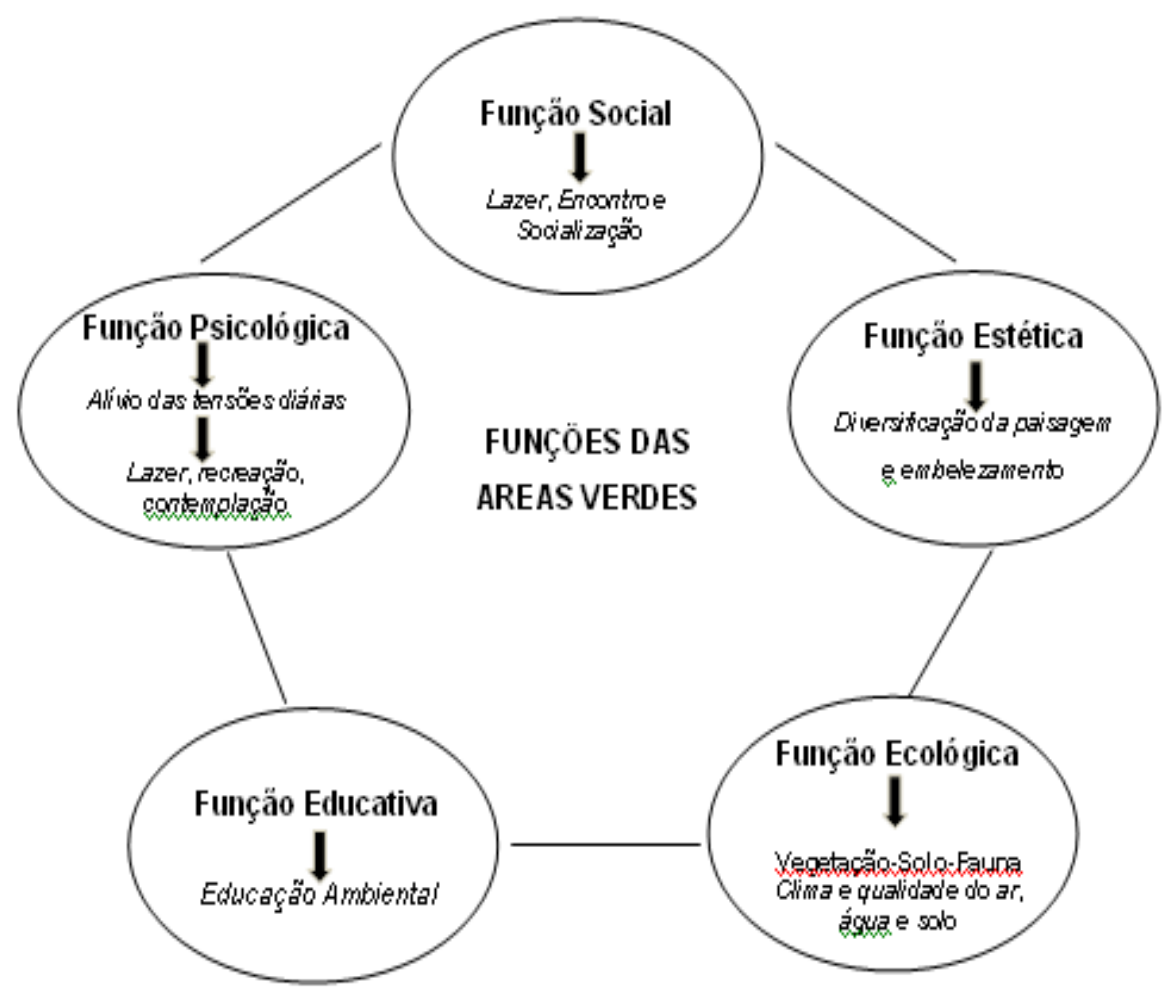

Fonte: Bargos, 2010; Modificado a partir de Vieira, 2004.

Sendo assim, para ele, as funções destas áreas estariam relacionadas à: 
$\checkmark$ Função Social: possibilidade de lazer que essas áreas oferecem à população. Com relação a este aspecto, deve-se considerar a necessidade de hierarquização.

$\checkmark$ Função Estética: diversificação da paisagem construída e embelezamento da cidade. Relacionada a este aspecto deve ser ressaltada a importância da vegetação.

$\checkmark$ Função ecológica: provimento de melhorias no clima da cidade e na qualidade do ar, água e solo, resultando no bem estar dos habitantes, devido à presença da vegetação, do solo não impermeabilizado e de uma fauna mais diversificada nessas áreas.

$\checkmark$ Função Educativa: possibilidade oferecida por tais espaços como ambiente para o desenvolvimento de atividades educativas, extraclasse e de programas de educação ambiental.

$\checkmark$ Função Psicológica: possibilidade de realização de exercícios, de lazer e de recreação que funcionam como atividades "antiestresse" e relaxamento, uma vez que as pessoas entram em contato com os elementos naturais dessas áreas.

É importante salientar que a manutenção das áreas verdes é extremamente importante para que estas possam cumprir plenamente suas funções, sendo preciso considerar que elas devem estar devidamente conservadas.

\section{Classificação das áreas verdes}

A diversidade de critérios para categorização das áreas verdes urbanas é um elemento importante na análise e comparação entre os índices de áreas verdes urbanas elaborados para diferentes localidades. Não somente a falta de uma definição consensual, mas também um grande número de metodologias para seleção e mapeamento das áreas verdes vem dificultando o desenvolvimento de trabalhos com esse enfoque. Enquanto em alguns trabalhos as áreas verdes são mapeadas sem seguir critérios de classificação ou categorização, em outros se percebe a preocupação com uma classificação que seja a mais adequada à área de estudo. 
Cavalheiro e Del Picchia (1992) sugerem uma classificação para os espaços livres que pode auxiliar na diferenciação entre as áreas verdes e os outros tipos de espaços livres. Conforme os autores os espaços livres podem ser classificados segundo sua tipologia, ou seja, se são particulares, potencialmente coletivos ou públicos e, na sequência, segundo categorias, como, por exemplo, praças, jardins, verde viário. Com base na proposta de Cavalheiro et al.. (1999), Buccheri e Nucci (2006) elaboraram um organograma de classificação para o verde urbano (Figura 2).

Figura 2. Organograma de Classificação do Verde Urbano

Figure 2. Organizational Chart of Classification of Urban Green

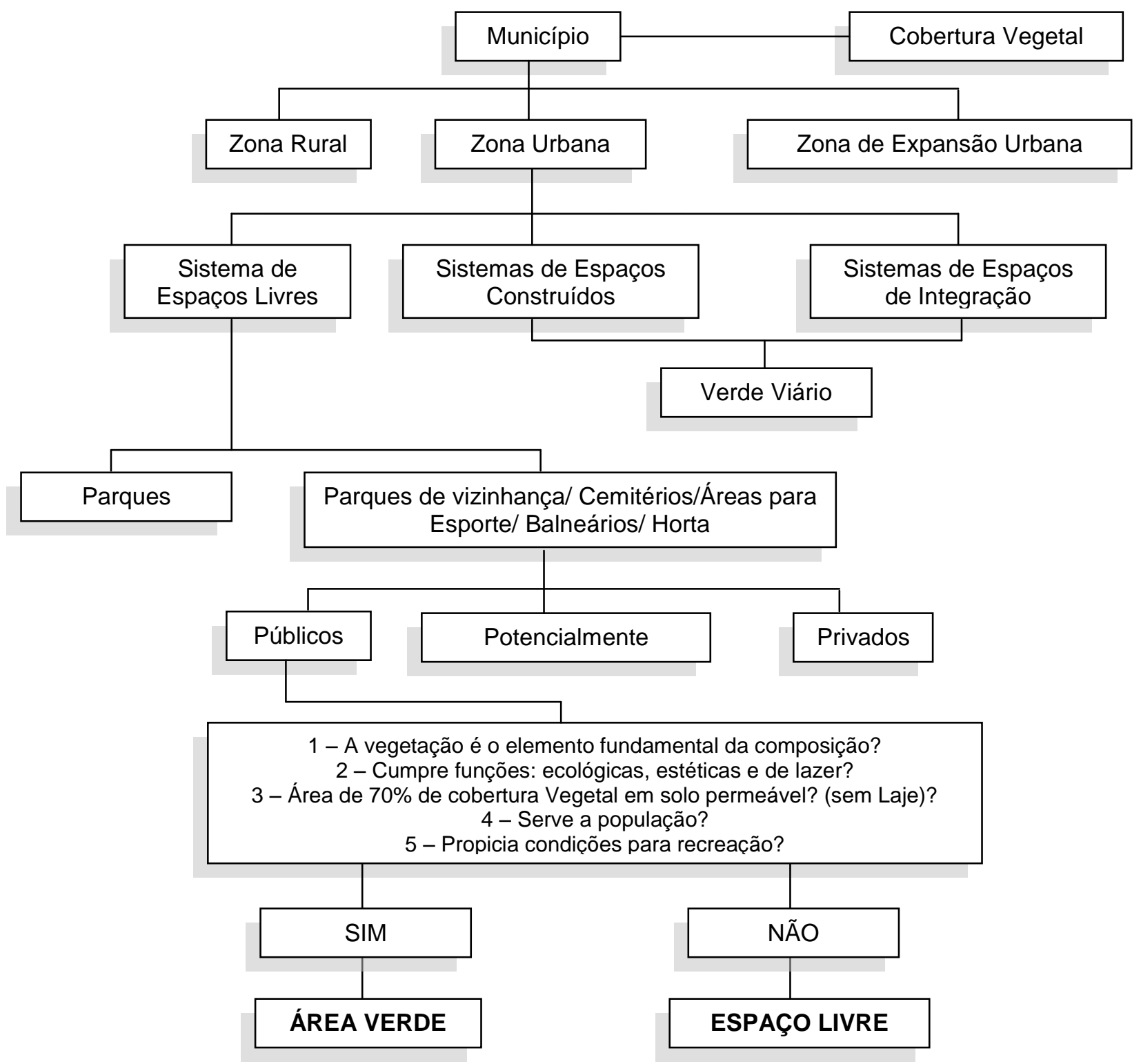


Outros pesquisadores, entre os quais Oliveira (1996), Zanin (2002) e Rosset (2005), se utilizaram de um modelo de classificação de áreas verdes públicas, modificado conforme os objetivos propostos por cada pesquisador em seus trabalhos. Conforme Rosset (2005):

A utilização do MCAVP [Modelo de Classificação de Áreas Verdes Públicas] consiste em navegar por uma chave de múltiplas escolhas, na qual o resultado é a definição de classes que considera elementos estruturais, funcionais e utilitários das áreas verdes públicas. $\mathrm{O}$ procedimento para a classificação das áreas verdes públicas tem início com base em uma grande classe: 1 - áreas pertencentes ao sistema viário em região urbanizada [...] o sistema de codificação das classes é dado pela sucessão de algarismos numéricos definidos ao se navegar pelo MCAVP (ROSSET, 2005, p. 20).

Oliveira (1996, p. 35) argumenta que, embora o MCAVP permita o estabelecimento de dezenas de classes distintas, é necessário o reconhecimento de que a classificação é um processo analítico e que o grande número de classes geradas se constitui em uma barreira para a elaboração do estudo por ele proposto. Dessa forma, ele considerou a necessidade de formar "grupos", onde cada um dos oito grupos definidos reúne um determinado número de classes que guardem em si características de interesse comum (Quadro 1). Nesta perspectiva o autor considera que "[...] a definição de grupos de classes de áreas públicas não é um processo analítico, mas sim de síntese".

Tabela 1. Descrição de três grupos de área verdes com base no Modelo de Classificação de Áreas Verdes Públicas.

Table 1. Description of three groups of green areas based on the Classification Model of Public Green Areas.

\begin{tabular}{|c|l|l|}
\hline Grupo & \multicolumn{2}{|c|}{ Descrição } \\
\hline A & $\begin{array}{l}\text { Áreas livres de acompanhamento viário não arborizadas ou apenas com vegetação } \\
\text { herbácea, refletindo baixo valor ecológico e estético. }\end{array}$ \\
\hline B & Áreas públicas com valor ecológico & $\begin{array}{l}\text { - Subgrupo 1: Verde de acompanhamento } \\
\text { viário, representando os canteiros centrais }\end{array}$ \\
\hline
\end{tabular}




\begin{tabular}{|l|l|l|}
\hline & $\begin{array}{l}\text { e estético frequentemente elevados, } \\
\text { contudo, com valor social } \\
\text { comprometido devido a problemas } \\
\text { de acessibilidade ou à sua situação } \\
\text { frente às condições de trânsito local. }\end{array}$ & $\begin{array}{l}\text { ou trevos/rotatórias arborizadas. } \\
\text { coletivas, pela sua localização interna a } \\
\text { condomínios ou a outros espaços de acesso } \\
\text { restrito a grupos específicos de indivíduos, } \\
\text { além de áreas inacessíveis por falta de } \\
\text { infraestrutura para visitação, representadas } \\
\text { por remanescentes de silvicultura e } \\
\text { vegetação nativa. }\end{array}$ \\
\hline C & $\begin{array}{l}\text { Representa as áreas verdes de uso coletivo, destacando-se, frequentemente, por } \\
\text { alto valor ecológico, estético e, sobretudo, social. Neste grupo está situada a maioria } \\
\text { das praças, bosques e parques da cidade. }\end{array}$ \\
\hline
\end{tabular}

Fonte: Modificado de Oliveira,1996.

É importante salientar que o conhecimento da localização e a classificação das áreas verdes no espaço urbano são de fundamental importância para que os responsáveis pelo poder público possam direcionar suas ações no controle, manutenção e ampliação dessas áreas. Neste sentido, é cada vez mais constante a preocupação com o raio de influência que estas áreas podem exercem em seu entorno.

Em seu trabalho, Rosset (2005) registra que um grupo de pesquisadores tem utilizado metodologias que consideram o raio de influência dos serviços proporcionados pelas áreas verdes urbanas, nas adjacências das mesmas, possibilitando distribuir tais benefícios, adicionalmente, às áreas vizinhas, sejam bairros, setores, distritos. O procedimento básico para a utilização desta metodologia consiste em definir o traçado de uma figura geométrica para cada área verde na qual o seu benefício seja quantificado em termos de densidade (DAV), resultante da razão entre a superfície da área verde $\left(\mathrm{m}^{2}\right)$ e a superfície da área de distribuição dos benefícios $\left(\mathrm{km}^{2}\right)$.

Uma área de influência para áreas verdes é definida por Oliveira (1996, p. 51) como "[...] uma medida da distância máxima hipotética que se espere que uma pessoa caminhe para atingi-la, a partir de sua residência", e pode ser determinado diretamente em termo de distância, ou estimado indiretamente baseado no tempo de percurso entre as residências e as áreas verdes. A vantagem desta técnica, segundo este pesquisador, é que quanto maior for o número de elementos provedores/consumidores de bens e serviços, no caso as áreas verdes, maior será o número de áreas de

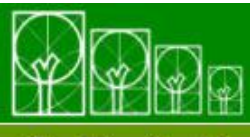

$\mathbf{S} \cdot \mathbf{B} \cdot \mathbf{A} \cdot \mathbf{U}$ Soc. Bras. de Arborização Urbana 
influência e, por decorrência, maior será a resolução espacial obtida nos modelos aplicados. No entanto,

[...] ao contrário do que sugere a conceitualização de "área de influência", as relações reais de oferta/demanda por serviços urbanos não seguem necessariamente um padrão isodiamétrico ou geográfico ideal e nem tampouco apresentam limites espaciais e temporais muito bem definidos (OLIVEIRA, 1996, p. 41).

Assim como a vantagem, a desvantagem da utilização desta metodologia também foi identificada por Oliveira (1996). Na definição da área de influência cada polígono estaria associado a um e somente um elemento em questão, uma área verde. Esta afirmação pode ser errônea na medida em que certo cidadão pode escolher desfrutar de outras áreas verdes de seu bairro ou cidade que não as mais próximas de sua casa, seja para fins de lazer, convívio social ou outros.

\section{CONCLUSÃO}

A questão relacionada à utilização do termo áreas verdes merece destaque nos debates atuais, pois o uso indistinto deste termo para designar a presença de vegetação no ambiente urbano pode induzir a uma interpretação e utilização incorreta destas áreas nas cidades.

Diante do exposto, entende-se que um conceito para áreas verdes urbanas deve considerar que elas sejam uma categoria de espaço livre urbano composta por vegetação arbórea e arbustiva (inclusive pelas árvores das vias públicas, desde que estas atinjam um raio de influência que as capacite a exercer as funções de uma área verde), com solo livre de edificações ou coberturas impermeabilizantes (em pelo menos $70 \%$ da área), de acesso público ou não, e que exerçam minimamente as funções ecológicas (aumento do conforto térmico, controle da poluição do ar e acústica, interceptação das águas das chuvas, e abrigo à fauna), estéticas (valorização visual e ornamental do ambiente e diversificação da paisagem construída) e de lazer (recreação).

Assim, além de quantificadas, essas áreas precisam ser qualificadas como tal. A dificuldade desta qualificação se encontra na valoração dos benefícios por elas trazidos, sejam valores ecológicos, estéticos, sociais ou financeiros, enquanto que 
para a quantificação as dificuldades se relacionam à classificação das mesmas. Ainda não se chegou a um consenso relacionado a este aspecto. Acredita-se que as áreas verdes podem ser classificadas segundo o porte da vegetação, e suas funções, pois se entende que estes podem ser aspectos que contribuem para ambientes saudáveis e agradáveis e que propiciam interações entre a sociedade e a natureza.

Como indicador de qualidade ambiental as áreas verdes precisam ser consideradas ainda conforme sua distribuição e dimensão espacial para que o planejamento urbano e ambiental supra as necessidades da sociedade e não apenas seja conduzido à valorização e preservação da vegetação no meio urbano por uma questão meramente preservacionista.

\section{REFERÊNCIAS BIBLIOGRÁFICAS}

BUCCHERI FILHO, A.T; NUCCI, J.C. Espaços Livres, Áreas Verdes e Cobertura Vegetal no Bairro Alto da XV, Curitiba - PR. Revista do Departamento de Geografia, v. 18, p.48-59, 2006.

CAVALHEIRO, F.; DEL PICCHIA, P.C.D. Áreas verdes: conceitos, objetivos e diretrizes para o planejamento. In: Anais... 1ํㅡ Congresso Brasileiro sobre Arborização Urbana e 4ํㅡㄹ Encontro Nacional sobre Arborização Urbana. Vitória, ES, 1992. p. 29-38.

CAVALHEIRO, F.; NUCCI, J.C.; GUZZO, P.; ROCHA, Y.T. Proposição de Terminologia para o Verde Urbano. Boletim Informativo da Sociedade Brasileira de Arborização Urbana. Rio de Janeiro, RJ, Ano VII, n. 3, jul/ago/set. 1999.

GUZZO, P. Cadastro Municipal de Espaços Livres Urbanos de Ribeirão Preto (SP): Acesso Público, Índices e Base para Novos Instrumentos e Mecanismos de Gestão. Revista da Sociedade Brasileira de Arborização Urbana, v.1, n.1, 2006.

HÜLSMEYER, A.F; SOUZA, R.C.A. Avaliação das áreas permeáveis como subsídio ao planejamento de áreas verdes urbanas de Umuarama- PR. Akrópolis, Umuarama, PR, v.15, n. 1 e 2, p 49 -59, jan/jun. 2007. 
JESUS, S.C.; BRAGA, R. Análise Espacial das Áreas Verdes Urbanas da Estância de Águas de São Pedro - SP. Caminhos de Geografia, v.18, n.16, p. 207- 224, out. 2005.

LIMA, A. M. L.P; CAVALHEIRO, F.; NUCCI, J.C.; SOUSA, M.A.L.B.; FIALHO, N. DEL PICCHIA, P.C.D. Problemas de utilização na conceituação de termos como espaços livres, áreas verdes e correlatos. In: Anais... II Congresso de Arborização Urbana. São Luis, MA, 1994. p. 539-553.

LOBODA, C.R.; DE ANGELIS, B.L.D. Áreas Verdes Públicas Urbanas: Conceitos, Usos e Funções. Ambiência. Guarapuava, PR, v.1, n.1, p. 125-139, jan./jun, 2005.

NUCCI, J.C. Qualidade ambiental e adensamento urbano. São Paulo, SP: Humanitas, 2001.

MAZZEI, K.; COLSESANTI, M.T.M.; SANTOS, D.G. Áreas verdes urbanas, espaços livres para o lazer. Sociedade \& Natureza, Uberlândia, MG, v.19, n.1, p 33-43, jun. 2007.

MORERO, A.M.; SANTOS, R.F.; FIDALGO, E.C.C. Planejamento ambiental de áreas verdes: estudo de caso de Campinas-SP. Revista do Instituto Florestal, v. 19, n. 1, p. 19-30, jun. 2007.

OLIVEIRA, C.H. Planejamento ambiental na cidade de São Carlos (SP) com ênfase nas áreas públicas e áreas verdes: diagnóstico e propostas. Dissertação (Mestrado em Ecologia e Recursos Naturais) - Universidade Federal de São Carlos, São Carlos, SP, 1996.

ROSSET, F. Procedimentos Metodológicos para estimativa do índice de áreas verdes públicas. Estudo de caso: Erexim, RS. Dissertação (Mestrado em Ecologia e Recursos Naturais) - Universidade Federal de São Carlos, São Carlos, SP, 2005.

TOLEDO, F.S; SANTOS, D.G. Espaços Livres de Construção. Revista da Sociedade Brasileira de Arborização Urbana, Piracicaba, SP, v.3, n.1, p. 73-91, mar. 2008. 
VIEIRA, P. B. H. Uma visão geográfica das áreas verdes de Florianópolis, SC: estudo de caso do Parque Ecológico do Córrego Grande (PECG). Universidade Federal de Santa Catarina. Trabalho de Conclusão de Curso, Florianópolis, SC, 2004.

ZANIN, E. M. Caracterização Ambiental da paisagem urbana de Erechim e do Parque Municipal Longines Malinowski. Erechim-RS. Tese (Doutorado em Ecologia e Recursos Naturais) - Universidade Federal de São Carlos, São Carlos, SP, 2002. 